\title{
Controlling the stereochemistry in 2-oxo-aldehyde-derived Ugi adducts through the cinchona alkaloid-promoted electrophilic fluorination
}

\author{
Yuqing Wang ${ }^{1}$, Gaigai Wang ${ }^{1}$, Anatoly A. Peshkov²,3, Ruwei Yao ${ }^{1}$, Muhammad Hasan ${ }^{1}$, \\ Manzoor Zaman¹, Chao Liu ${ }^{1}$, Stepan Kashtanov, Olga P. Pereshivko ${ }^{* 1,2}$ \\ and Vsevolod A. Peshkov*1,2,5
}

\section{Full Research Paper}

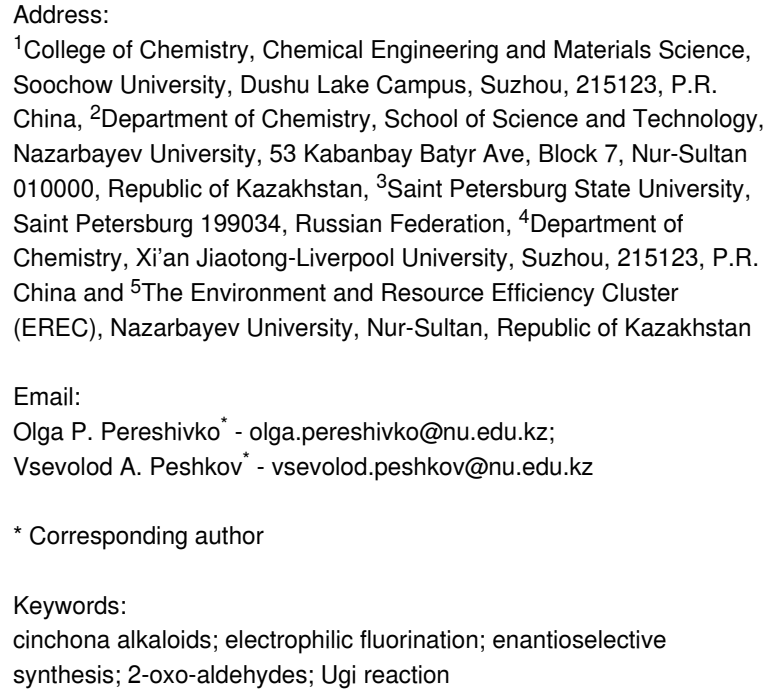

${ }^{1}$ College of Chemistry, Chemical Engineering and Materials Science, Soochow University, Dushu Lake Campus, Suzhou, 215123, P.R. China, ${ }^{2}$ Department of Chemistry, School of Science and Technology, Nazarbayev University, 53 Kabanbay Batyr Ave, Block 7, Nur-Sultan 010000, Republic of Kazakhstan, ${ }^{3}$ Saint Petersburg State University, Saint Petersburg 199034, Russian Federation, ${ }^{4}$ Department of Chemistry, Xi'an Jiaotong-Liverpool University, Suzhou, 215123, P.R. China and ${ }^{5}$ The Environment and Resource Efficiency Cluster (EREC), Nazarbayev University, Nur-Sultan, Republic of Kazakhstan

\section{Email:}

Olga P. Pereshivko* - olga.pereshivko@nu.edu.kz;

Vsevolod A. Peshkov* - vsevolod.peshkov@nu.edu.kz

* Corresponding author

Keywords:

cinchona alkaloids; electrophilic fluorination; enantioselective synthesis; 2-oxo-aldehydes; Ugi reaction

\author{
Beilstein J. Org. Chem. 2020, 16, 1963-1973. \\ doi:10.3762/bjoc. 16.163
}

Received: 06 June 2020

Accepted: 30 July 2020

Published: 11 August 2020

This article is part of the thematic issue "Organo-fluorine chemistry V".

Guest Editor: D. O'Hagan

(c) 2020 Wang et al.; licensee Beilstein-Institut.

License and terms: see end of document.

\begin{abstract}
In this report, we introduce a new strategy for controlling the stereochemistry in Ugi adducts. Instead of controlling stereochemistry directly during the Ugi reaction we have attempted to stereodefine the chiral center at the peptidyl position through the post-Ugi functionalization. In order to achieve this, we chose to study 2-oxo-aldehyde-derived Ugi adducts many of which partially or fully exist in the enol form that lacks the aforementioned chiral center. This in turn led to their increased nucleophilicity as compared to the standard Ugi adducts. As such, the stereocenter at the peptidyl position could be installed and stereodefined through the reaction with a suitable electrophile. Towards this end, we were able to deploy an asymmetric cinchona alkaloid-promoted electrophilic fluorination producing enantioenriched post-Ugi adducts fluorinated at the peptidyl position.
\end{abstract}

\section{Introduction}

Multicomponent reactions (MCRs) [1-13] in general and isocyanide-based MCRs [14-18] in particular represent powerful tools of modern synthetic chemistry that allow to generate structurally diverse and complex products in a step and atomeconomic manner from simple and accessible precursors. Three-component Passerini [19-22] and four-component Ugi 
$[23,24]$ reactions that rely on the ability of organic isocyanides to participate in the nucleophilic attack onto the carbonyl or imine group are among the most studied MCRs. Accordingly, a wide range of post-MCR transformations have been elaborated allowing to upgrade the Passerini and Ugi adducts into potentially bioactive heterocycles [25-32]. While both Passerini and Ugi reactions proved to be quite robust towards different classes of substrates and possess broad functional group tolerance, the difficulties associated with controlling their stereochemical outcome [33-35] severely restrict their applicability in medicinal chemistry [36].

The typical Passerini three-component reaction (P-3CR) of a carboxylic acid $\mathbf{1}$, an aldehyde $\mathbf{2}$, and an isocyanide $\mathbf{3}$ being conducted in a polar-aprotic solvent such as THF or dichloromethane results in the assembly of an $\alpha$-acyloxyamide adduct 4 . Just a few protocols for the asymmetric P-3CR [37-40] and its modifications [41-47] have been reported over the course of the last two decades (Table 1). In the majority of those protocols [37-39], the stereocontrol was achieved with the aid of different Lewis acid promoters bearing chiral ligands, while the most recent and at the same time the most general procedure developed by Liu, Tan and co-workers relied on the stereoinduction by a chiral phosphoric acid (Table 1) [40].

In the standard Ugi four-component reaction (U-4CR) a carboxylic acid $\mathbf{1}$, an aldehyde $\mathbf{2}$, and an isocyanide $\mathbf{3}$ are complemented by a primary amine $\mathbf{5}$ that altogether undergo a

Table 1: Asymmetric protocols for Passerini three-component reaction (P-3CR).

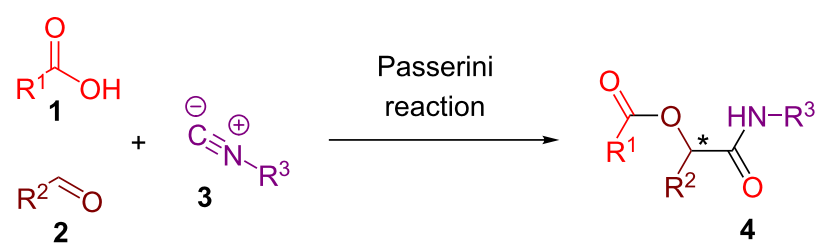

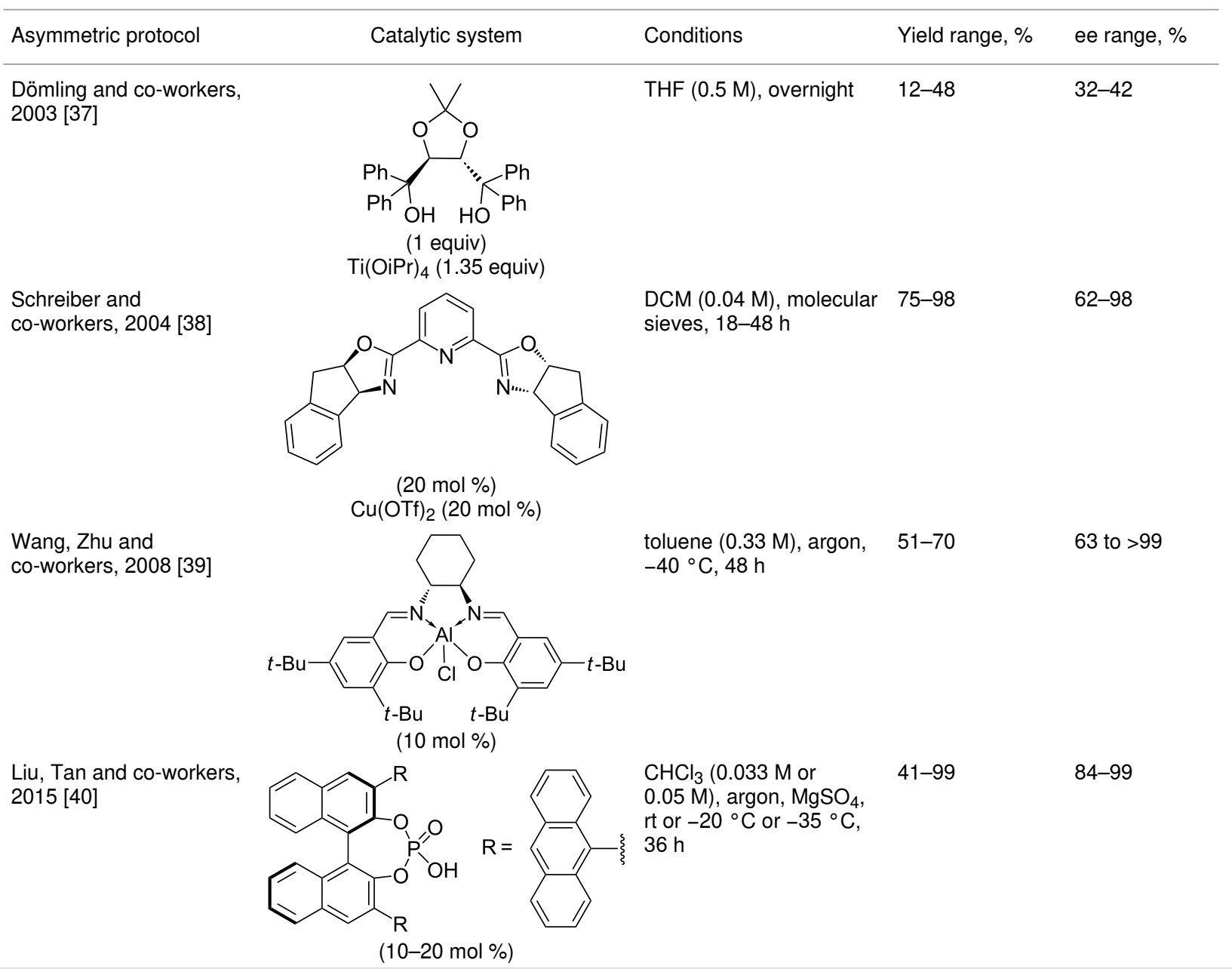


condensation into a peptide-like adduct $\mathbf{6}$. These reactions are typically conducted in polar protic solvents such as methanol or water. Several examples of diastereoselective U-4CR have been described [48-54]. Yet, the Ugi reaction turned out to be a rather challenging chemical transformation in terms of establishing the asymmetric version [33-35]. Apart from the two asymmetric three-component modifications lacking the acid component [55,56], no general asymmetric protocol for the four-component mode has been developed until very recently. In 2018, Houk, Tan and co-workers described an efficient enantioselective procedure operating in the presence of catalytic amounts of chiral phosphoric acids (Table 2) [57]. Two synthetic protocols have been elaborated allowing the engagement of different classes of substrates (Table 2). In addition, the group of Tan adapted their findings to the chiral phosphoric acid-catalyzed three-component Ugi reaction of an aldehyde $\mathbf{2}$, an isocyanide $\mathbf{3}$, and a primary amine $\mathbf{5}$ [58].

As a part of our ongoing research, we have been involved in the synthesis and utilization of 2-oxo-aldehyde-derived Ugi adducts
8 (Scheme 1). These products possess an increased nucleophilicity of the peptidyl position compared to the standard Ugi adducts owing to an additional electron-withdrawing group introduced with the 2-oxo-aldehyde 7 . For example, we have explored the potential of the peptidyl reactive site in a number of enolization-driven post-Ugi cyclizations leading to the assembly of pyrrol-2-ones $\mathbf{9}$ and $\mathbf{1 0}$ [59,60]. We have also taken advantage of a 1,3-dicarbonyl moiety present in $\mathbf{8}$ by engaging them in an enolization-triggered complexation with boron trifluoride diethyl etherate. The resulting $O, O$-chelated boron complexes 11 turned out to be strong solid-state emitters featuring clear aggregation-induced emission (AIE) characteristics [61].

Encouraged by these results, we decided to attempt the reaction of 2-oxo-aldehyde-derived Ugi adducts 8 with suitable electrophiles in the presence of chiral catalyst or promotor. In this way, the peptidyl position of $\mathbf{8}$ could be simultaneously functionalized and stereodefined leading to the formation of enantioenriched products 12 (Scheme 1). Towards this goal, we have

Table 2: Asymmetric protocols for Ugi four-component reaction (U-4CR) by Houk, Tan and co-workers.

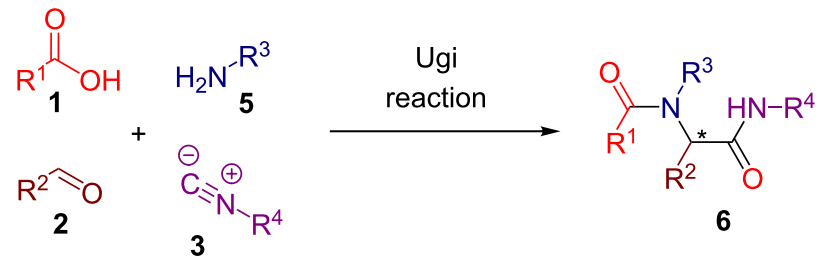

\begin{tabular}{|c|c|c|c|c|}
\hline Substrate scope & Catalytic system & Conditions & Yield range, \% & ee range, $\%$ \\
\hline $\mathrm{R}^{2}=\mathrm{Alk} ; \mathrm{R}^{3}=\mathrm{Ar}$ & & $\begin{array}{l}\mathrm{DCM}(0.05 \mathrm{M}) \text {, argon, } 5 \AA \\
\mathrm{MS},-20^{\circ} \mathrm{C}, 12 \mathrm{~h}\end{array}$ & $43-96$ & $75-97$ \\
\hline $\mathrm{R}^{2}=\mathrm{Ar} ; \mathrm{R}^{3}=\mathrm{Alk}$ & & $\begin{array}{l}\text { cyclohexane }(0.025 \mathrm{M}) \text {, } \\
\text { argon, } 5 \AA \mathrm{MS}, 20^{\circ} \mathrm{C} \text {, } \\
36 \mathrm{~h}-7 \mathrm{~d}\end{array}$ & $60-96$ & 80-94 \\
\hline
\end{tabular}




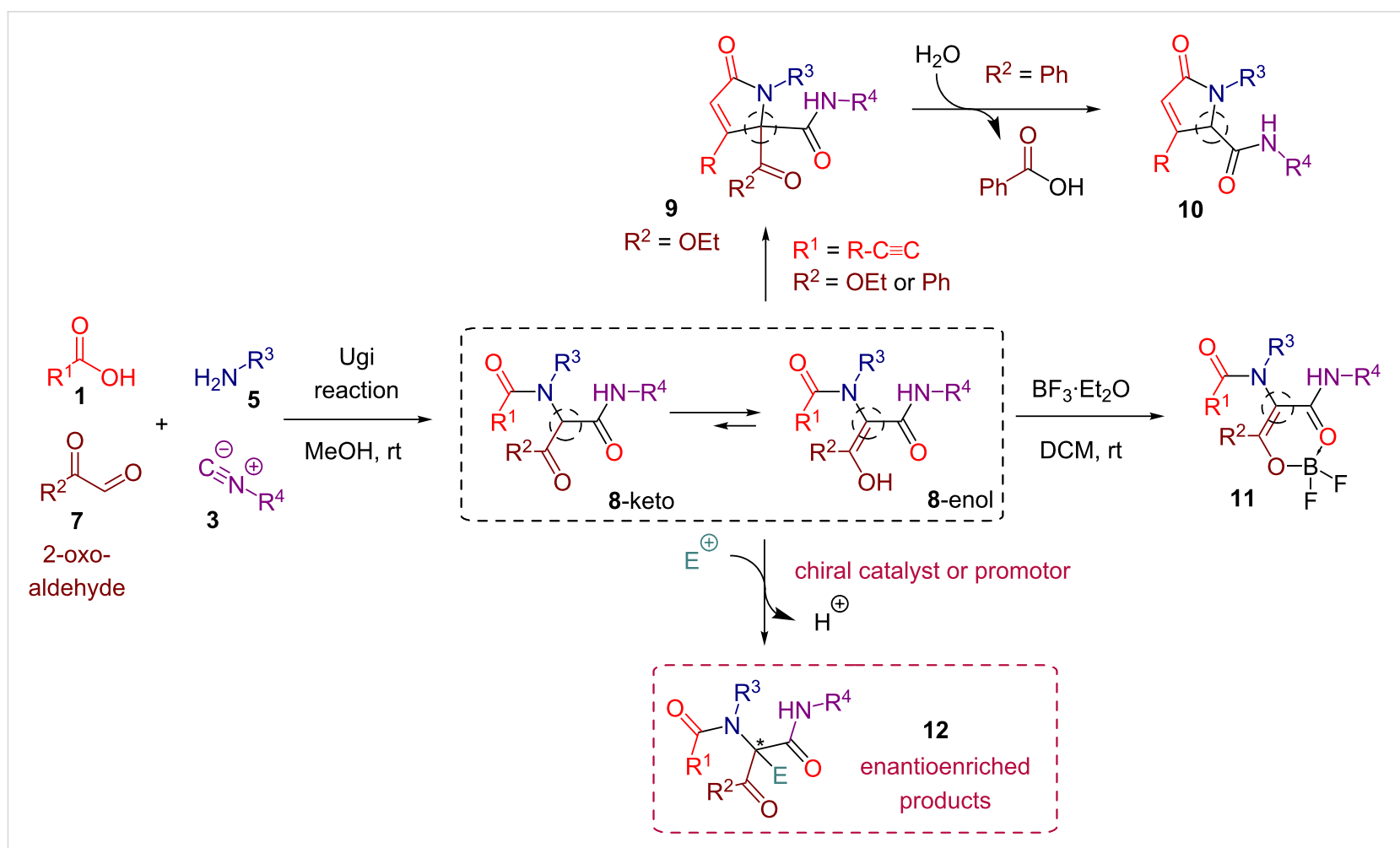

Scheme 1: Post-transformations of 2-oxo-aldehyde-derived Ugi adducts 8.

previously tested the reactivity of $\mathbf{8}$ in the intermolecular aldol addition to ethyl glyoxalate [62]. As these attempts met with failure, we have turned our attention to enantioselective fluorination reactions [63-65]. Specifically, we decided to explore the enantioselective electrophilic fluorination of carbonyl compounds promoted by cinchona alkaloid derivatives developed independently by Shibata, Takeuchi and co-workers $[65,66]$ and by the group of Cahard [67-70]. The method proved to be applicable to a broad range of substrates under a variety of conditions [71-78] and was successfully utilized for the synthesis of several bioactive molecules [79-81]. Herein we present its adaptation for the enantioselective fluorination of 2-oxo-aldehyde-derived Ugi adducts 8 leading to the installment of a fluorine-bound quaternary stereocenter at the peptidyl position. It should be stressed that the exploration of methods for the enantioselective fluorination continues to be an important topic considering the ever-growing role of fluorine derivatives in drug design and development $[82,83]$. An alternative strategy to prepare related quaternary carbon-containing adducts bearing fluorine and nitrogen atoms involves the asymmetric addition of $\alpha$-fluoro- $\beta$-ketoesters or $\alpha$-fluoro- $\alpha$-nitro esters to appropriate electrophiles [84-89].

\section{Results and Discussion}

Initially, we prepared a series of Ugi adducts $\mathbf{8}$ by varying acid, 2-oxo-aldehyde, amine, and isocyanide components
(Scheme 2). The product 8a obtained from benzoic acid, phenylglyoxal, benzylamine, and tert-butyl isocyanide was selected for the screening of the reaction parameters (Table 3). The overall process was conducted in a two-step one-pot fashion as was originally designed by Shibata. In the first step, a cinchona alkaloid derivative was allowed to react with an electrophilic fluorinating agent to afford an $\mathrm{N}$-fluoroammonium salt of the cinchona alkaloid via transfer fluorination. In the second step, the Ugi adduct 8a was added to this in situ generated $\mathrm{N}$-fluorocinchona intermediate to afford the desired fluorinated product 12a. Thus, according to this synthetic and mechanistic path, the $N$-fluorocinchona intermediate acted as an asymmetric electrophilic fluorinating agent.

Conducting the fluorination of $8 \mathbf{a}$ with a quinine (Q)/Selectfluor combination in different solvents revealed chloroform as a preferred reaction medium for this process with acetonitrile, tetrahydrofuran, and dichloromethane being less efficient in terms of ee of the obtained product 12a (Table 3, entries 1-5). Using catalytic quantities of quinine led to a prolonged reaction time and diminished yield and ee of $\mathbf{1 2 a}$ compared to the analogous reaction with stoichiometric amounts of quinine (Table 3 , entry 4 versus entry 3 ). Thus, we focused on the exploration of a stoichiometric version considering that most of cinchona alkaloid derivatives are readily accessible and recoverable. The original Shibata's protocol also relied on the use of stoichio- 


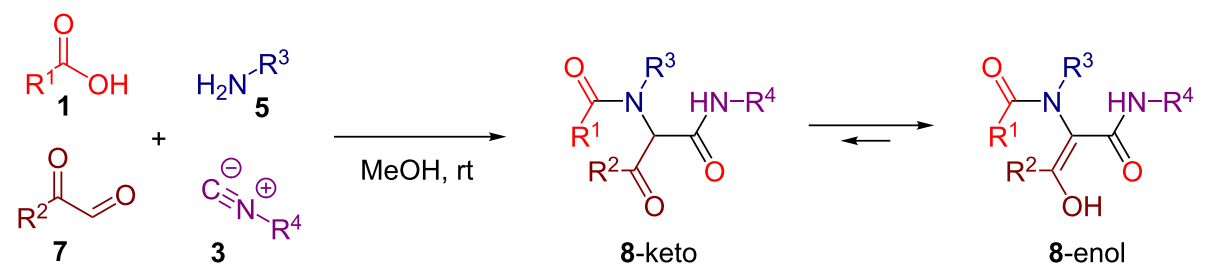

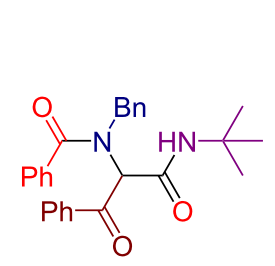

$8 a, 62 \%$

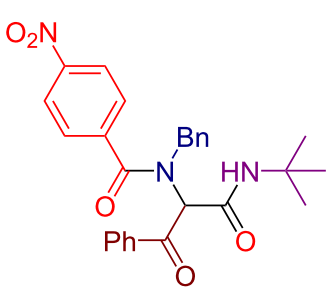

$\mathbf{8 b}, 79 \%$

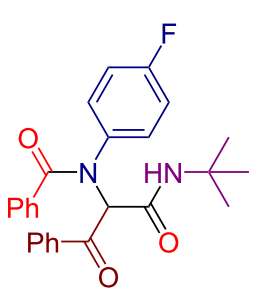

$8 f, 48 \%$

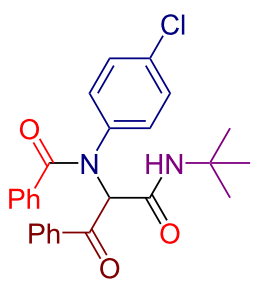

$\mathbf{8 g}, 39 \%$<smiles>CC(C)(C)NC(=O)C(C(=O)c1ccc(C#N)cc1)N(Cc1ccccc1)C(=O)c1ccccc1</smiles>

$8 c, 72 \%$<smiles>CC(C)(C)NC(=O)C(C(=O)c1ccccc1)N(C(=O)c1ccccc1)c1ccccc1</smiles>

$8 d, 67 \%$

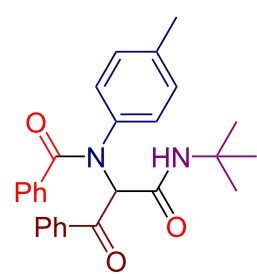

$8 e, 56 \%$

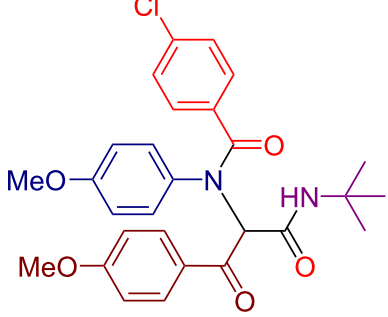

$8 \mathrm{~h}, 68 \%$

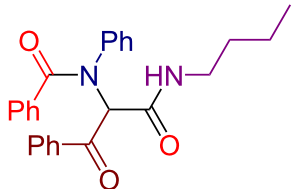

$8 i, 70 \%$

Scheme 2: Synthesis of 2-oxo-aldehyde-derived Ugi adducts.

metric amounts of the chiral promotor that was in an agreement with a two-step reaction mode requiring the initial formation of the asymmetric fluorinating agent. An attempt to use cupreine, a member of the cinchona family featuring free phenolic hydroxy group, met with failure producing no desired product $\mathbf{1 2 a}$ (Table 3, entry 6). Using dihydroquinine (DHQ) led to an improved ee of $\mathbf{1 2 a}$ compared to the analogous reactions with quinine (Table 3, entries 7 and 8 versus entries 5 and 2, respectively). Testing ether and ester derivatives of $Q$ and DHQ (Table 3, entries 9-12) led to further improvement allowing to obtain 12a with up to $73 \%$ ee through the reaction with dihydroquinine benzyl ether (DHQ-Bn, Table 3, entry 12). Switching to quinidine (QD), dihydroquinidine (DHQD), and their derivatives allowed to alter the stereoselectivity of the process leading to the preferred formation of another enantiomer of 12a (Table 3, entries 13-18) with the QD-promoted reaction affording the best ee value (Table 3, entry 13). Additionally, we tested $N$-fluorobenzenesulfonimide (NFSI) as an alternative fluorinating agent in a combination with DHQ-Bn and QD with the outcome being indistinguishable with the analogous reactions with Selectfluor.

Having these results in hand, we moved to investigating the scope and limitation of this procedure with the Ugi adducts $\mathbf{8}$ obtained previously (Table 4). In order to have a more balanced representation we decided to test most of these substrates $\mathbf{8}$ with eight different cinchona alkaloid derivatives including $\mathrm{Q}, \mathrm{DHQ}$, QD, DHQD, and their benzyl ether derivatives. To assure reproducibility, some of these reactions were repeated two to five times. In all such cases a range for the yield and ee value is reported in Table 4. Testing Ugi adducts $\mathbf{8 b}$ and $\mathbf{8 c}$ that similarly to 8a were obtained from benzylamine and tert-butyl isocyanide by varying either acid or 2-oxo-aldehyde components revealed that it was difficult to achieve high enantioselectivity for such substrates. Specifically, none of the studied chiral promoters could afford the desired products $12 \mathbf{b}$ and $12 \mathrm{c}$ with the ee value consistently higher than $50 \%$. Turning to the substrates $8 \mathbf{d}-\mathbf{g}$ derived from aromatic amines we were able to achieve improved enantioselectivity. The best results were obtained with Q-Bn, DHQ-Bn, DHQD, and QD-Bn that performed consistently well with each of the substrates $\mathbf{8 d}-\mathbf{g}$ delivering the corresponding fluorinated products $12 \mathbf{d}-\mathbf{g}$ with the ee values higher than $50 \%$ and in some cases close or even over $70 \%$. Furthermore, it was possible to divert the selectivity of these reactions towards the preferred formation of either of the enantiomers by choosing an appropriate chiral promotor. Testing Ugi adduct $\mathbf{8 h}$ allowed us to highlight the possibility of simultaneous variation of acid, 2-oxo-aldehyde, and amine compo- 
Table 3: Screening of the conditions for enantioselective fluorination of Ugi adduct $\mathbf{8 a}$ a $^{\text {a }}$

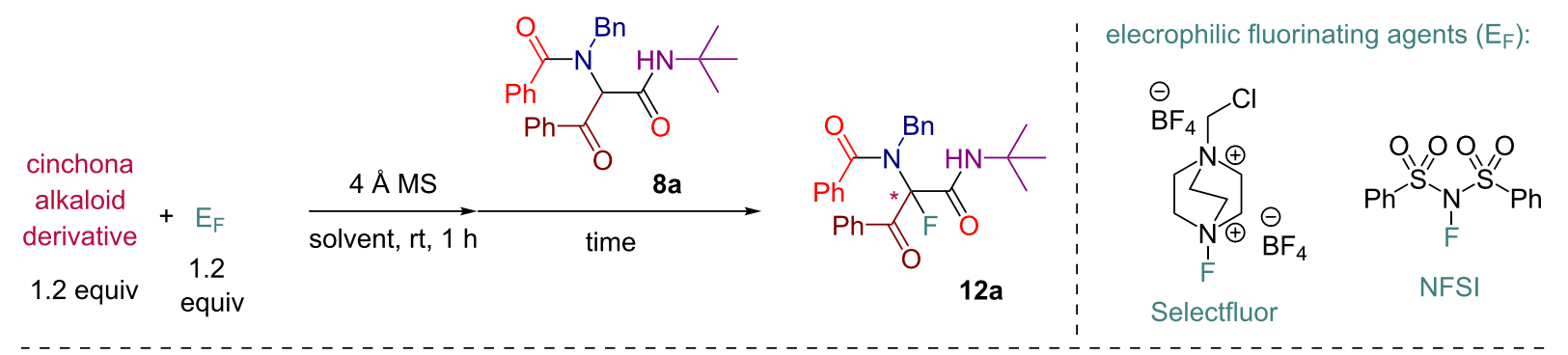

cinchona alkaloid derivatives:

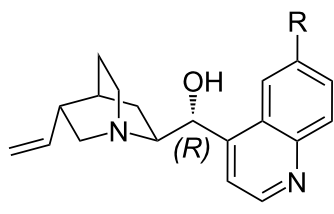

$\mathrm{R}=\mathrm{OMe}$, quinine $\mathrm{Q}$

$\mathrm{R}=\mathrm{OH}$, cupreine $\mathrm{CPN}$<smiles>CCC1CN2C3CCC(C3)N1C2[C@H](O)c1ccnc2ccc(OC)cc12</smiles>

dihydroquinine $\mathrm{DHQ}$<smiles>[R]OC([2H])c1ccnc2ccc(OC)cc12</smiles>

$\mathrm{R}=\mathrm{Bn}, \mathrm{Q}-\mathrm{Bn}$

$\mathrm{R}=\mathrm{Ac}, \mathrm{Q}-\mathrm{Ac}$

$\mathrm{R}=\mathrm{Me}, \mathrm{Q}-\mathrm{Bz}$<smiles>CCO[C@H](c1ccnc2ccc(OC)cc12)C1C2CCN1CC2CC</smiles>

DHQ-Bn<smiles>C=CC1C2CCN1C(C)C2C(O)c1ccnc2ccc(OC)cc12</smiles>

quinidine $\mathrm{QD}$<smiles>CCC1CC2CCN1C(C)C2(O)c1ccnc2ccc(OC)cc12</smiles>

dihydroquinidine $\mathrm{DHQD}$<smiles>[R]C(C)c1ccnc2ccc(OC)cc12</smiles>

$\mathrm{R}=\mathrm{Me}, \mathrm{QD}-\mathrm{Me}$ $\mathrm{R}=\mathrm{Bn}, \mathrm{QD}-\mathrm{Bn}$ $\mathrm{R}=\mathrm{Ac}, \mathrm{QD}-\mathrm{Ac}$<smiles>CCC1C2CCN1C(Cc1ccnc3ccc(OC)cc13)C2[Ge](C)(C)C</smiles>

DHQD-Bn

\begin{tabular}{|c|c|c|c|c|c|c|}
\hline Entry & $\begin{array}{l}\text { Cinchona alkaloid } \\
\text { derivative }\end{array}$ & Fluorinating agent & Solvent & Time, $\mathrm{h}$ & Yield, ${ }^{\mathrm{b}} \%$ & ee (major enantiomer), ${ }^{\mathrm{C}} \%$ \\
\hline 1 & $Q$ & Selectfluor & $\mathrm{MeCN}$ & 23 & 88 & $19(F)$ \\
\hline 2 & $Q$ & Selectfluor & THF & 19 & 94 & $21(F)$ \\
\hline 3 & Q & Selectfluor & $\mathrm{DCM}$ & 21 & 74 & $26(F)$ \\
\hline $4^{d}$ & $Q$ & Selectfluor & $\mathrm{DCM}$ & 70 & 42 & $20(F)$ \\
\hline 5 & Q & Selectfluor & $\mathrm{CHCl}_{3}$ & 21 & $71-79$ & $31-44(F)$ \\
\hline 6 & CPN & Selectfluor & $\mathrm{CHCl}_{3}$ & 21 & $-^{e}$ & $-^{e}$ \\
\hline 7 & $\mathrm{DHQ}$ & Selectfluor & $\mathrm{CHCl}_{3}$ & $16-21$ & $85-90$ & $46-57(F)$ \\
\hline 8 & $\mathrm{DHQ}$ & Selectfluor & THF & 12 & 76 & $43(F)$ \\
\hline 9 & Q-Bn & Selectfluor & $\mathrm{CHCl}_{3}$ & 21 & $78-83$ & $39-41(F)$ \\
\hline 10 & Q-Ac & Selectfluor & $\mathrm{CHCl}_{3}$ & $21-24$ & $35-59$ & $42-51(F)$ \\
\hline 11 & Q-Bz & Selectfluor & $\mathrm{CHCl}_{3}$ & 20 & 62 & $32(F)$ \\
\hline 12 & DHQ-Bn & Selectfluor or NFSI & $\mathrm{CHCl}_{3}$ & $16-22$ & $60-81$ & $57-73(F)$ \\
\hline 13 & QD & Selectfluor or NFSI & $\mathrm{CHCl}_{3}$ & $21-23$ & $83-94$ & $51-69(\mathrm{~S})$ \\
\hline 14 & DHQD & Selectfluor & $\mathrm{CHCl}_{3}$ & 21 & $86-92$ & $15-21(\mathrm{~S})$ \\
\hline 15 & QD-Me & Selectfluor & $\mathrm{CHCl}_{3}$ & 23 & 75 & $14(\mathrm{~S})$ \\
\hline 16 & QD-Ac & Selectfluor & $\mathrm{CHCl}_{3}$ & 20 & 29 & $27(S)$ \\
\hline 17 & QD-Bn & Selectfluor & $\mathrm{CHCl}_{3}$ & 21 & 80 & $29(S)$ \\
\hline 18 & DHQD-Bn & Selectfluor & $\mathrm{CHCl}_{3}$ & 21 & 87 & $23(S)$ \\
\hline
\end{tabular}

aThe reactions were run on a $0.15-0.2 \mathrm{mmol}$ scale; bisolated yield; ' ${ }^{\mathrm{C}}$ determined by chiral HPLC analysis, S: slower enantiomer, F: faster enantiomer;

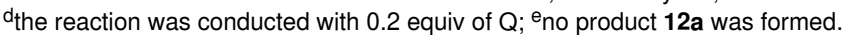


nents. Overall, four cinchona derivatives were screened with $\mathbf{8 h}$ producing the fluorinated product $\mathbf{1 2 h}$ with moderate to good enantioselectivity, which was consistent with the performance of other arylamine-derived Ugi adducts $\mathbf{8 d}-\mathbf{g}$. The last investigated Ugi adduct $8 \mathbf{i}$ featured the variation of the isocyanide component. Conducting fluorinations with this $n$-butyl isocyanide-derived Ugi adduct $\mathbf{8 i}$, the desired product $\mathbf{1 2} \mathbf{i}$ could be successfully obtained. However, the degree of enantioselective induction was lower than in the reactions with the analogous tert-butyl isocyanide-derived substrate 8d. This could probably be ascribed to a reduced rigidity and bulkiness of the $n$-butyl group as compared to tert-butyl.
For the substrates $\mathbf{8 a}-\mathbf{g}$ tested with eight cinchona alkaloid derivatives fluorinations with QD and DHQD led to the reversed stereoselectivity as compared to the reactions with $\mathrm{Q}$ and DHQ. For the benzylamine-derived substrates 8a-c benzyl ether derivatives of cinchona alkaloids favored the formation of the same enantiomer of $\mathbf{1 2}$ as their free alcohol counterparts (e.g., both Q-Bn and Q favored the formation of the same enantiomer of 12). In contrast, for the substrates $\mathbf{8 d - g}$ derived from aromatic amines a reversed trend was observed. In case of $\mathbf{8 d}-\mathbf{g}$, benzyl ether derivatives of cinchona alkaloids favored the formation of the opposite enantiomer of $\mathbf{1 2}$ as compared to the one favored by the parent alkaloids featuring free alcohol

Table 4: Scope and limitations of the asymmetric electrophilic fluorination of 2-oxo-aldehyde-derived Ugi adducts 8 . $^{\text {a }}$

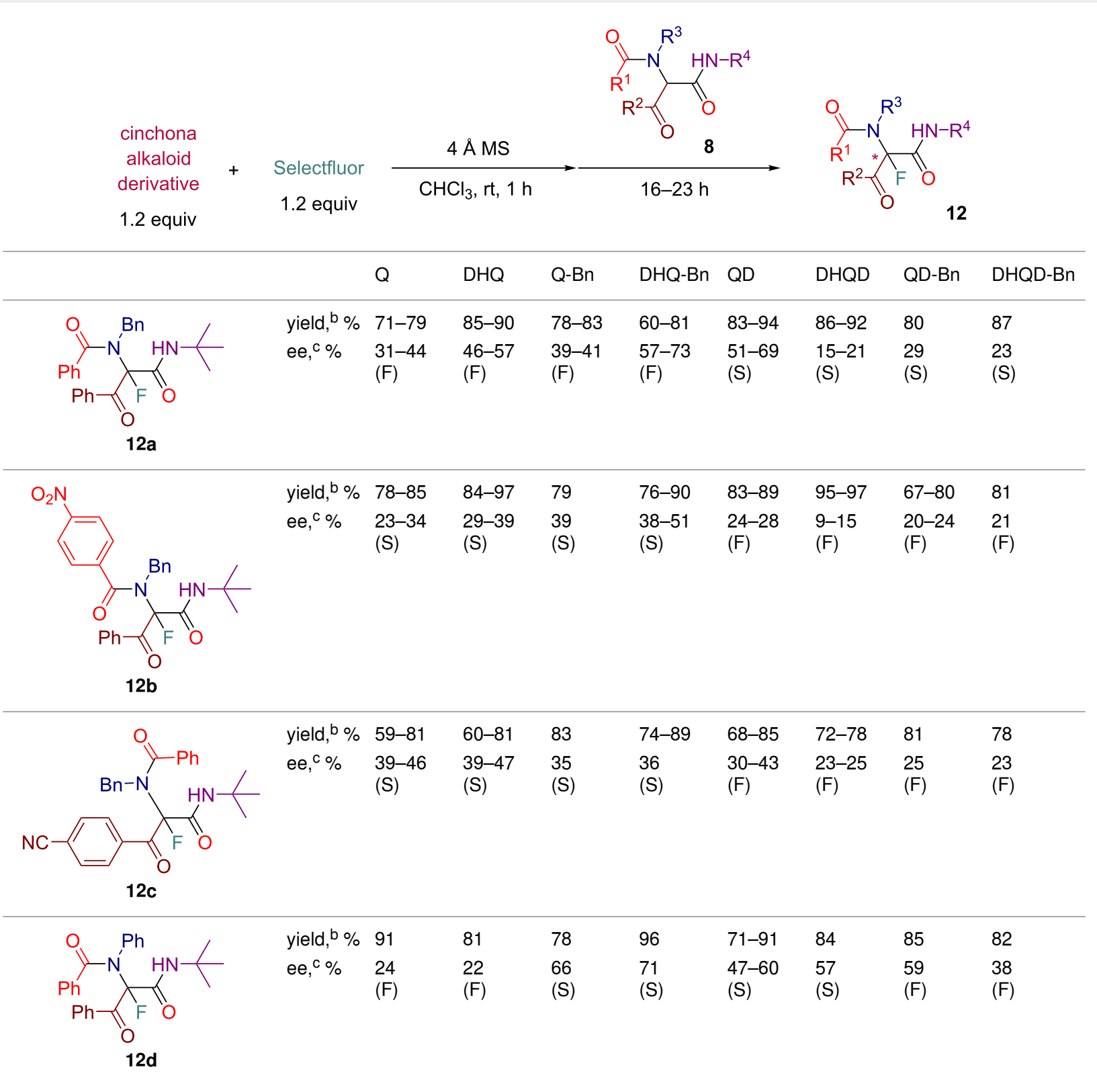


Table 4: Scope and limitations of the asymmetric electrophilic fluorination of 2-oxo-aldehyde-derived Ugi adducts 8 a $^{\text {(continued) }}$

$\begin{array}{llllllllll} & \text { yield, }{ }^{\mathrm{b}} \% & 68-78 & 91-97 & 78-82 & 86-97 & 89-98 & 84-91 & 95-98 & 85 \\ & \text { ee, }{ }^{\mathrm{c}} \% & 18-30 & 19-23 & 65-69 & 71-74 & 49-50 & 58-65 & 61-67 & 42 \\ & & (\mathrm{~F}) & (\mathrm{F}) & (\mathrm{S}) & (\mathrm{S}) & (\mathrm{S}) & (\mathrm{S}) & (\mathrm{F}) & (\mathrm{F})\end{array}$<smiles>[Z20]OC(=O)C(F)(C(=O)NC(C)(C)C)N(C(=O)c1ccccc1)C(=O)c1ccccc1</smiles>

(S)

(F)<smiles>CC(C)(C)NC(=O)C(F)(C(=O)c1ccccc1)N(C(=O)c1ccccc1)c1ccc(F)cc1</smiles>

$\begin{array}{lllllllll}\text { yield, }{ }^{\text {b } \%} & 88-89 & 91-92 & 84-88 & 85-86 & 71-78 & 89-98 & 89 & 79 \\ \text { ee, }{ }^{c \%} & 23-27 & 18-19 & 66-67 & 69-72 & 50-55 & 53-64 & 57-58 & 40 \\ & (F) & (F) & (S) & (S) & (S) & (S) & (F) & (F)\end{array}$

$12 f$

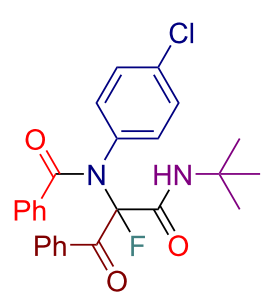

$\begin{array}{lllll}\text { yield, }^{\text {b } \%} & 74-85 & 90 & 82-84 & 86-87 \\ \text { ee, }{ }^{\mathrm{C}} \% & 25-37 & 18-24 & 65-66 & 63-70\end{array}$

82-88

75-76

48-59

75-76

75-84

78-81

(F)

(F)

(S)

(S)

(S)

(S)

59-60
(F)

37-54

(F)

$12 \mathrm{~g}$

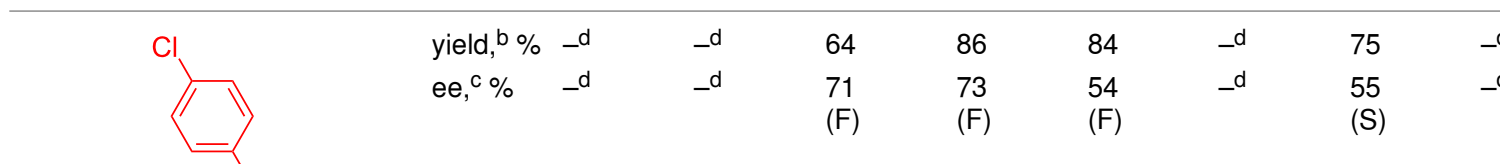<smiles>C/C=C(/C)C(=O)N(c1ccc(OC)cc1)C(F)(C(=O)NC(C)(C)C)C(=O)c1ccc(OC)cc1</smiles>

$12 \mathrm{~h}$

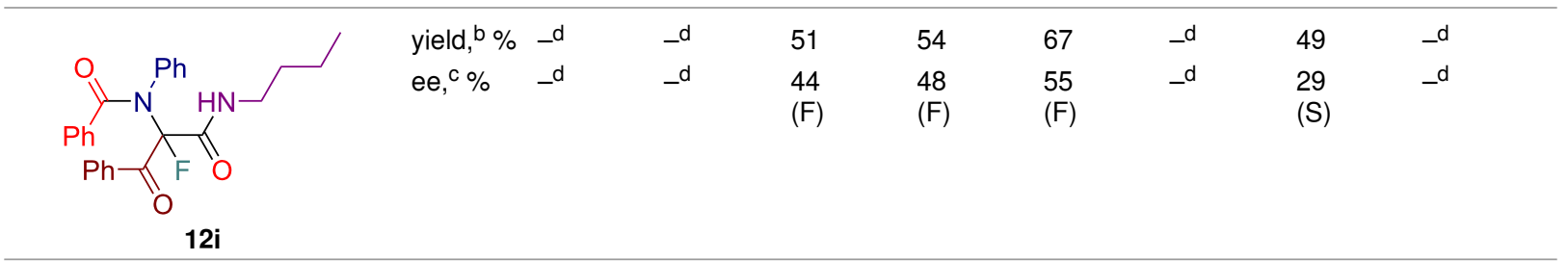

aThe reactions were run on a $0.15-0.2 \mathrm{mmol}$ scale; bisolated yield; ' determined by chiral HPLC analysis, S: slower enantiomer, F: faster enantiomer; dnot conducted.

moiety (e.g., Q-Bn favored the formation of the enantiomer of 12 with the absolute configuration opposite to the one favored by Q). Substrates $\mathbf{8 h}$ and $\mathbf{8 i}$ were tested with only four cinchona alkaloid derivatives, but the observed stereochemical trends appeared to be consistent with those established for the rest of arylamine-derived Ugi adducts $\mathbf{8 d}-\mathbf{g}$.
Finally, we attempted to determine the absolute configuration of a stereocenter for the major enantiomer of the representative fluorinated product. Using a sample of product 12e with the ee value of $74 \%$ we were able to obtain crystals suitable for the structure determination via X-ray crystallographic analysis. It was found that a part of the substance crystallized in a racemic 
form while the rest crystallized in an enantiopure form. By resolving both types of crystals [90], the configuration of the major slow enantiomer was successfully established as $S$ (Figure 1).

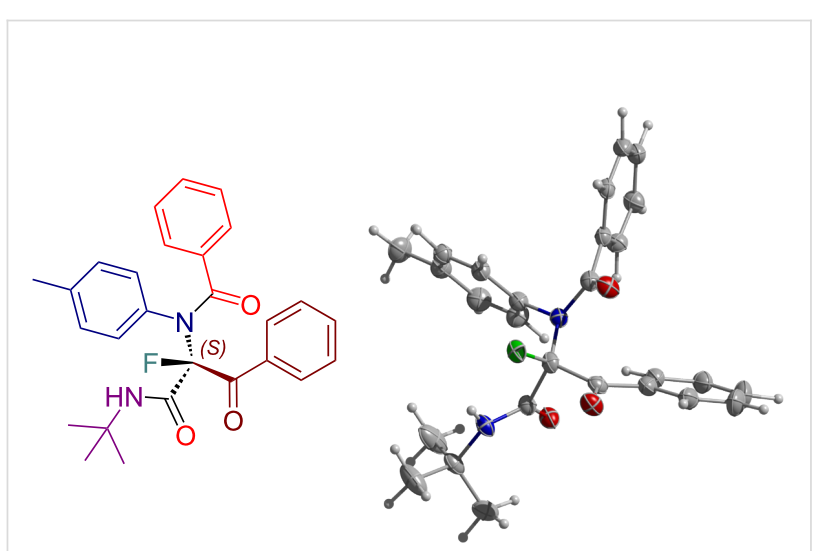

Figure 1: Molecular representation of the X-ray crystal structure of $(S)$-12e (slow enantiomer).

\section{Conclusion}

In summary, we have explored a new strategy for controlling the stereochemistry in the Ugi adducts through the enantioselective post-Ugi functionalization. Specifically, we have adapted the cinchona alkaloid-promoted asymmetric electrophilic fluorination for derivatizing the 2-oxo-aldehyde-derived Ugi adducts. This allowed us to obtain the post-Ugi products fluorinated at the peptidyl position with the enantiomeric excess values in several instances reaching more than $70 \%$.

\section{Supporting Information}

\section{Supporting Information File 1}

Experimental procedures, characterization data and copies of spectra.

[https://www.beilstein-journals.org/bjoc/content/ supplementary/1860-5397-16-163-S1.pdf]

\section{Supporting Information File 2}

Crystallographic data (CIF) for compound (S)-12e. [https://www.beilstein-journals.org/bjoc/content/ supplementary/1860-5397-16-163-S2.cif]

\section{Supporting Information File 3}

Crystallographic data (CIF) for compound (rac)-12e. [https://www.beilstein-journals.org/bjoc/content/ supplementary/1860-5397-16-163-S3.cif]

\section{Acknowledgements}

We thank Prof. Xingwang Wang for his advice to explore the electrophilic fluorination as a tool for the enantioselective postUgi functionalization.

\section{Funding}

This work was supported by the start-up fund from Soochow University (grant Q410900714), National Natural Science Foundation of China (grant 21650110445), Natural Science Foundation of Jiangsu Province of China (grant BK20160310), the Priority Academic Program Development of Jiangsu Higher Education Institutions (PAPD) and the project of scientific and technologic infrastructure of Suzhou (grant SZS201708). M.H. and M.Z. are grateful to the Chinese Scholarship Council (CSC) for providing doctoral scholarships.

\section{References}

1. Bienaymé, H.; Hulme, C.; Oddon, G.; Schmitt, P. Chem. - Eur. J. 2000, 6, 3321-3329.

doi:10.1002/1521-3765(20000915)6:18<3321::aid-chem3321>3.0.co;2a

2. Zhu, J.; Bienaymé, H., Eds. Multicomponent Reactions, 1st ed.; Wiley-VCH: Weinheim, Germany, 2005. doi:10.1002/3527605118

3. Sunderhaus, J. D.; Martin, S. F. Chem. - Eur. J. 2009, 15, 1300-1308. doi:10.1002/chem.200802140

4. Ganem, B. Acc. Chem. Res. 2009, 42, 463-472. doi:10.1021/ar800214s

5. Orru, R. V. A.; Ruijter, E., Eds. Synthesis of Heterocycles via Multicomponent Reactions I; Topics in Heterocyclic Chemistry; Springer: Heidelberg, Germany, 2010. doi:10.1007/978-3-642-12675-8

6. Orru, R. V. A.; Ruijter, E., Eds. Synthesis of Heterocycles via Multicomponent Reactions II; Topics in Heterocyclic Chemistry; Springer: Heidelberg, Germany, 2010. doi:10.1007/978-3-642-15455-3

7. Jiang, B.; Rajale, T.; Wever, W.; Tu, S.-J.; Li, G. Chem. - Asian J. 2010, 5, 2318-2335. doi:10.1002/asia.201000310

8. Dömling, A.; Wang, W.; Wang, K. Chem. Rev. 2012, 112, 3083-3135. doi:10.1021/cr100233r

9. Zhu, J.; Wang, Q.; Wang, M.-X., Eds. Multicomponent Reactions in Organic Synthesis; Wiley-VCH: Weinheim, Germany, 2014. doi:10.1002/9783527678174

10. Banfi, L.; Basso, A.; Moni, L.; Riva, R. Eur. J. Org. Chem. 2014, 2005-2015. doi:10.1002/ejoc.201301715

11. Cioc, R. C.; Ruijter, E.; Orru, R. V. A. Green Chem. 2014, 16, 2958-2975. doi:10.1039/c4gc00013g

12. Levi, L.; Müller, T. J. J. Chem. Soc. Rev. 2016, 45, 2825-2846. doi:10.1039/c5cs00805k

13. Murlykina, M. V.; Morozova, A. D.; Zviagin, I. M.; Sakhno, Y. I.; Desenko, S. M.; Chebanov, V. A. Front. Chem. (Lausanne, Switz.) 2018, 6, 527. doi:10.3389/fchem.2018.00527

14. Dömling, A.; Ugi, I. Angew. Chem., Int. Ed. 2000, 39, 3168-3210. doi:10.1002/1521-3773(20000915)39:18<3168::aid-anie3168>3.0.co;2u

15. Akritopoulou-Zanze, I. Curr. Opin. Chem. Biol. 2008, 12, 324-331. doi:10.1016/j.cbpa.2008.02.004

16. Koopmanschap, G.; Ruijter, E.; Orru, R. V. A. Beilstein J. Org. Chem. 2014, 10, 544-598. doi:10.3762/bjoc. 10.50 
17. Váradi, A.; Palmer, T. C.; Notis Dardashti, R.; Majumdar, S. Molecules 2016, 21, 19. doi:10.3390/molecules21010019

18. Bode, M. L.; Gravestock, D.; Rousseau, A. L. Org. Prep. Proced. Int. 2016, 48, 89-221. doi:10.1080/00304948.2016.1138072

19. Passerini, M. Gazz. Chim. Ital. 1921, 51, 126-129.

20. Banfi, L.; Riva, R. Org. React. 2005, 65, 1-140. doi:10.1002/0471264180.or065.01

21. Kazemizadeh, A. R.; Ramazani, A. Curr. Org. Chem. 2012, 16, 418-450. doi:10.2174/138527212799499868

22. Chandgude, A. Multicomponent Reactions: Development, Scope, and Applications. Ph.D. Thesis, University of Groningen, Groningen, Netherlands, 2017.

23. Ugi, I.; Meyr, R.; Fetzer, U.; Steinbrückner, C. Angew. Chem. 1959, 71, 386. doi:10.1002/ange.19590711110

24. Ugi, I.; Steinbrückner, C. Angew. Chem. 1960, 72, 267-268. doi:10.1002/ange.19600720709

25. Banfi, L.; Basso, A.; Riva, R. Synthesis of Heterocycles Through Classical Ugi and Passerini Reactions Followed by Secondary Transformations Involving One or Two Additional Functional Groups. In Synthesis of Heterocycles via Multicomponent Reactions I; Orru, R. V. A.; Ruijter, E., Eds.; Topics in Heterocyclic Chemistry, Vol. 23; Springer: Berlin, Germany, 2010; pp 1-39. doi:10.1007/7081_2009_23

26. Sharma, U. K.; Sharma, N.; Vachhani, D. D.; Van der Eycken, E. V. Chem. Soc. Rev. 2015, 44, 1836-1860. doi:10.1039/c4cs00253a

27. Zhang, Z.; Zheng, X.; Guo, C. Chin. J. Org. Chem. 2016, 36 , 1241-1265. doi:10.6023/cjoc201511004

28. Li, X.; Jia, X.; Yin, L. Chin. J. Org. Chem. 2017, 37, 2237-2249. doi:10.6023/cjoc201704026

29. Banfi, L.; Basso, A.; Lambruschini, C.; Moni, L.; Riva, R. Chem. Heterocycl. Compd. 2017, 53, 382-408. doi:10.1007/s10593-017-2065-1

30. Heravi, M. M.; Mohammadkhani, L. Synthesis of various $\mathrm{N}$-heterocycles using the four-component Ugi reaction. Advances in Heterocyclic Chemistry; Elsevier: Amsterdam, Netherlands, 2020; Vol. 131, pp 351-403. doi:10.1016/bs.aihch.2019.04.001

31. Bariwal, J.; Kaur, R.; Voskressensky, L. G.; Van der Eycken, E. V. Front. Chem. (Lausanne, Switz.) 2018, 6, 557. doi:10.3389/fchem.2018.00557

32. Mohammadi-Khanaposhtani, M.; Jalalimanesh, N.; Saeedi, M.; Larijani, B.; Mahdavi, M. Mol. Diversity 2020, 24, 855-887. doi:10.1007/s11030-019-09975-y

33. Wang, Q.; Wang, D.-X.; Wang, M.-X.; Zhu, J. Acc. Chem. Res. 2018, 51, 1290-1300. doi:10.1021/acs.accounts.8b00105

34. Shaabani, S.; Dömling, A. Angew. Chem., Int. Ed. 2018, 57, 16266-16268. doi:10.1002/anie.201811129

35. Riva, R. Science 2018, 361, 1072-1073. doi:10.1126/science.aau7497

36. Huang, Y.; Wolf, S.; Koes, D.; Popowicz, G. M.; Camacho, C. J.; Holak, T. A.; Dömling, A. ChemMedChem 2012, 7, 49-52. doi:10.1002/cmdc.201100428

37. Kusebauch, U.; Beck, B.; Messer, K.; Herdtweck, E.; Dömling, A. Org. Lett. 2003, 5, 4021-4024. doi:10.1021/ol035010u

38. Andreana, P. R.; Liu, C. C.; Schreiber, S. L. Org. Lett. 2004, 6, 4231-4233. doi:10.1021/ol0482893

39. Wang, S.-X.; Wang, M.-X.; Wang, D.-X.; Zhu, J. Angew. Chem., Int. Ed. 2008, 47, 388-391. doi:10.1002/anie.200704315

40. Zhang, J.; Lin, S.-X.; Cheng, D.-J.; Liu, X.-Y.; Tan, B. J. Am. Chem. Soc. 2015, 137, 14039-14042. doi:10.1021/jacs.5b09117
41. Denmark, S. E.; Fan, Y. J. Org. Chem. 2005, 70, 9667-9676. doi:10.1021/jo050549m

42. Wang, S.; Wang, M.-X.; Wang, D.-X.; Zhu, J. Eur. J. Org. Chem. 2007, 4076-4080. doi:10.1002/ejoc.200700340

43. Wang, S.-X.; Wang, M.-X.; Wang, D.-X.; Zhu, J. Org. Lett. 2007, 9, 3615-3618. doi:10.1021/ol7014658

44. Yue, T.; Wang, M.-X.; Wang, D.-X.; Zhu, J. Angew. Chem., Int. Ed. 2008, 47, 9454-9457. doi:10.1002/anie.200804213

45. Yue, T.; Wang, M.-X.; Wang, D.-X.; Masson, G.; Zhu, J. J. Org. Chem. 2009, 74, 8396-8399. doi:10.1021/j09017765

46. Mihara, H.; Xu, Y.; Shepherd, N. E.; Matsunaga, S.; Shibasaki, M. J. Am. Chem. Soc. 2009, 131, 8384-8385. doi:10.1021/ja903158x

47. Zeng, X.; Ye, K.; Lu, M.; Chua, P. J.; Tan, B.; Zhong, G. Org. Lett. 2010, 12, 2414-2417. doi:10.1021/ol1007789

48. Gulevich, A. V.; Balenkova, E. S.; Nenajdenko, V. G. J. Org. Chem. 2007, 72, 7878-7885. doi:10.1021/j0071030o

49. Nenajdenko, V. G.; Gulevich, A. V.; Chernichenko, K. Y.; Sokolova, N. V.; Balenkova, E. S. Mendeleev Commun. 2011, 21, 245-246. doi:10.1016/j.mencom.2011.09.004

50. Banfi, L.; Basso, A.; Cerulli, V.; Rocca, V.; Riva, R. Beilstein J. Org. Chem. 2011, 7, 976-979. doi:10.3762/bjoc.7.109

51. Banfi, L.; Basso, A.; Chiappe, C.; De Moliner, F.; Riva, R.; Sonaglia, L. Org. Biomol. Chem. 2012, 10, 3819-3829. doi:10.1039/c2ob25060h

52. Zhu, D.; Xia, L.; Pan, L.; Li, S.; Chen, R.; Mou, Y.; Chen, X. J. Org. Chem. 2012, 77, 1386-1395. doi:10.1021/j02021967

53. Caputo, S.; Basso, A.; Moni, L.; Riva, R.; Rocca, V.; Banfi, L. Beilstein J. Org. Chem. 2016, 12, 139-143. doi:10.3762/bjoc.12.15

54. Lambruschini, C.; Moni, L.; Banfi, L. Eur. J. Org. Chem. 2020, 3766-3778. doi:10.1002/ejoc.202000016

55. Hashimoto, T.; Kimura, H.; Kawamata, Y.; Maruoka, K. Angew. Chem., Int. Ed. 2012, 51, 7279-7281. doi:10.1002/anie.201201905

56. Zhao, W.; Huang, L.; Guan, Y.; Wulff, W. D. Angew. Chem., Int. Ed. 2014, 53, 3436-3441. doi:10.1002/anie.201310491

57. Zhang, J.; Yu, P.; Li, S.-Y.; Sun, H.; Xiang, S.-H.; Wang, J.; Houk, K. N.; Tan, B. Science 2018, 361, eaas8707. doi:10.1126/science.aas8707

58. Zhang, J.; Wang, Y.-Y.; Sun, H.; Li, S.-Y.; Xiang, S.-H.; Tan, B. Sci. China: Chem. 2020, 63, 47-54. doi:10.1007/s11426-019-9606-2

59. Nechaev, A. A.; Peshkov, A. A.; Peshkov, V. A.; Van der Eycken, E. V. Synthesis 2016, 48, 2280-2286. doi:10.1055/s-0035-1561422

60. Peshkov, A. A.; Peshkov, V. A.; Li, Z.; Pereshivko, O. P.; Van der Eycken, E. V. Eur. J. Org. Chem. 2014, 6390-6393. doi:10.1002/ejoc.201402723

61. Wei, H.; Wang, G.; Wang, Y.; Li, B.; Huang, J.; Kashtanov, S.; Van Hecke, K.; Pereshivko, O. P.; Peshkov, V. A. Chem. - Asian J. 2017, 12, 825-829. doi:10.1002/asia.201700051

62. Hasan, M.; Zaman, M.; Peshkov, A. A.; Amire, N.; Les, A.; Nechaev, A. A.; Wang, Y.; Kashtanov, S.; Van der Eycken, E. V.; Pereshivko, O. P.; Peshkov, V. A. Eur. J. Org. Chem. 2020, 3378-3389. doi:10.1002/ejoc.202000015

63. Shibata, N.; Ishimaru, T.; Nakamura, S.; Toru, T. J. Fluorine Chem. 2007, 128, 469-483. doi:10.1016/j.jluchem.2006.12.014

64. Lectard, S.; Hamashima, Y.; Sodeoka, M. Adv. Synth. Catal. 2010, 352, 2708-2732. doi:10.1002/adsc.201000624

65. Shibatomi, K.; Narayama, A.; Soga, Y.; Muto, T.; Iwasa, S. Org. Lett. 2011, 13, 2944-2947. doi:10.1021/ol201007e

66. Shibata, N.; Suzuki, E.; Takeuchi, Y. J. Am. Chem. Soc. 2000, 122, 10728-10729. doi:10.1021/ja002732x 
67. Shibata, N.; Suzuki, E.; Asahi, T.; Shiro, M. J. Am. Chem. Soc. 2001, 123, 7001-7009. doi:10.1021/ja010789t

68. Cahard, D.; Audouard, C.; Plaquevent, J.-C.; Roques, N. Org. Lett. 2000, 2, 3699-3701. doi:10.1021/ol006610l

69. Cahard, D.; Audouard, C.; Plaquevent, J.-C.; Toupet, L.; Roques, N. Tetrahedron Lett. 2001, 42, 1867-1869. doi:10.1016/s0040-4039(01)00017-x

70. Mohar, B.; Baudoux, J.; Plaquevent, J.-C.; Cahard, D. Angew. Chem., Int. Ed. 2001, 40, 4214-4216. doi:10.1002/1521-3773(20011119)40:22<4214::aid-anie4214>3.0.co;2b

71. Baudequin, C.; Plaquevent, J.-C.; Audouard, C.; Cahard, D. Green Chem. 2002, 4, 584-586. doi:10.1039/b208817g

72. Baudequin, C.; Loubassou, J.-F.; Plaquevent, J.-C.; Cahard, D. J. Fluorine Chem. 2003, 122, 189-193. doi:10.1016/s0022-1139(03)00085-x

73. Thierry, B.; Audouard, C.; Plaquevent, J.-C.; Cahard, D. Synlett 2004, 856-860. doi:10.1055/s-2004-817781

74. Mohar, B.; Sterk, D.; Ferron, L.; Cahard, D. Tetrahedron Lett. 2005, 46, 5029-5031. doi:10.1016/j.tetlet.2005.05.074

75. Fukuzumi, T.; Shibata, N.; Sugiura, M.; Nakamura, S.; Toru, T. J. Fluorine Chem. 2006, 127, 548-551. doi:10.1016/j.jfluchem.2006.01.004

76. Ramírez, J.; Huber, D. P.; Togni, A. Synlett 2007, 1143-1147. doi:10.1055/s-2007-973897

77. Yi, W.-B.; Huang, X.; Zhang, Z.; Zhu, D.-R.; Cai, C.; Zhang, W. Beilstein J. Org. Chem. 2012, 8, 1233-1240. doi:10.3762/bjoc.8.138

78. Wang, M.; Wang, B. M.; Shi, L.; Tu, Y. Q.; Fan, C.-A.; Wang, S. H.; Hu, X. D.; Zhang, S. Y. Chem. Commun. 2005, 5580-5582. doi:10.1039/b510004f

79. Shibata, N.; Ishimaru, T.; Suzuki, E.; Kirk, K. L. J. Org. Chem. 2003, 68, 2494-2497. doi:10.1021/j0026792s

80. Zoute, L.; Audouard, C.; Plaquevent, J.-C.; Cahard, D. Org. Biomol. Chem. 2003, 1, 1833-1834. doi:10.1039/b303113f

81. Shibata, N.; Ishimaru, T.; Nakamura, M.; Toru, T. Synlett 2004, 2509-2512. doi:10.1055/s-2004-834810

82. Gillis, E. P.; Eastman, K. J.; Hill, M. D.; Donnelly, D. J.; Meanwell, N. A. J. Med. Chem. 2015, 58, 8315-8359. doi:10.1021/acs.jmedchem.5b00258

83. Inoue, M.; Sumii, Y.; Shibata, N. ACS Omega 2020, 5, 10633-10640. doi:10.1021/acsomega.0c00830

84. Huber, D. P.; Stanek, K.; Togni, A. Tetrahedron: Asymmetry 2006, 17, 658-664. doi:10.1016/j.tetasy.2006.01.035

85. Mang, J.-Y.; Kim, D.-Y. Bull. Korean Chem. Soc. 2008, 29, 2091-2092. doi:10.5012/bkcs.2008.29.11.2091

86. Mang, J. Y.; Kwon, D. G.; Kim, D. Y. J. Fluorine Chem. 2009, 130, 259-262. doi:10.1016/j.jluchem.2008.11.001

87. Han, X.; Zhong, F.; Lu, Y. Adv. Synth. Catal. 2010, 352, 2778-2782. doi:10.1002/adsc.201000562

88. Cui, H.-F.; Li, P.; Wang, X.-W.; Chai, Z.; Yang, Y.-Q.; Cai, Y.-P.; Zhu, S.-Z.; Zhao, G. Tetrahedron 2011, 67, 312-317. doi:10.1016/j.tet.2010.11.041

89. Kwiatkowski, J.; Lu, Y. Org. Biomol. Chem. 2015, 13, 2350-2359. doi:10.1039/c4ob02486a

90. Crystallographic data for rac-12e (CCDC 2015756) and (S)-12e (CCDC 2015755) have been deposited with the Cambridge Crystallographic Data Centre.

\section{License and Terms}

This is an Open Access article under the terms of the Creative Commons Attribution License (http://creativecommons.org/licenses/by/4.0). Please note that the reuse, redistribution and reproduction in particular requires that the authors and source are credited.

The license is subject to the Beilstein Journal of Organic Chemistry terms and conditions: (https://www.beilstein-journals.org/bjoc)

The definitive version of this article is the electronic one which can be found at: doi:10.3762/bjoc. 16.163 